\title{
Reoperation after acute type A dissection: Is less more?
}

\author{
Leora B. Balsam, MD, ${ }^{a}$ and Abe DeAnda, $\mathrm{Jr}, \mathrm{MD}^{\mathrm{b}}$
}

\footnotetext{
From the ${ }^{\mathrm{a}}$ Division of Cardiac Surgery, UMass Memorial Medical Center, Worcester, Mass; and ${ }^{\mathrm{b}}$ Division of Cardiovascular and Thoracic Surgery, University of Texas Medical Branch-Galveston, Galveston, Tex. Disclosures: Authors have nothing to disclose with regard to commercial support.

Received for publication March 20, 2018; accepted for publication March 22, 2018; available ahead of print April $21,2018$.

Address for reprints: Leora B. Balsam, MD, Division of Cardiac Surgery, UMass Memorial Medical Center, University Campus, 55 Lake Ave N, Worcester, MA 01655 (E-mail: leora.balsam@umassmemorial.org).

J Thorac Cardiovasc Surg 2018;156:935-6

$0022-5223 / \$ 36.00$

Copyright (c) 2018 by The American Association for Thoracic Surgery

https://doi.org/10.1016/j.jtcvs.2018.03.084
}

The extent of resection and reconstruction required to treat an acute type A aortic dissection (ATAAD) successfully requires that we define what constitutes success. First and foremost is a live patient, something that is not a given for this particular pathology and is typically defined by operative and 30-day mortalities. Up for debate is the degree to which extensive proximal resection (for example, root replacement with a composite valve graft or valvesparing procedure) or distal repair (including total arch replacement and frozen elephant trunk technique) add to 30-day mortality. Depending on the center and its experience, similar early results have been reported with these techniques when compared with lesser resections. That said, a general consensus is that the surgeon's best bet is to perform a repair strategy that balances center-specific (and surgeon-specific) expertise, as well as patientspecific (and dissection-specific) characteristics.

When choosing a repair strategy, midterm and long-term survival are also important, and the occurrence of postoperative complications, such as stroke and myocardial infarction, matter. Less often discussed is the need for reoperation and whether the need is secondary to progression of disease or a result of an event directly tied to the original operation. In this issue of the Journal, Pan and colleagues ${ }^{1}$ review the Nordic experience with reoperation after repair of ATAAD, drawing data from the Nordic Consortium for Acute Type A Aortic Dissection (NORCAAD). Eight small to medium-sized cardiothoracic centers participate in NORCAAD, and each collects and submits data retrospectively to the registry. Between 2005 and 2014, more than 1000 consecutive patients undergoing repair for ATAAD were enrolled. A recent study from NORCAAD investigators reported 30-day mortality of $17.6 \%$ in this cohort, ${ }^{2}$ which is similar to the early outcomes from the International Registry of Acute Aortic Dissections. ${ }^{3}$ For NORCAAD patients surviving the initial operation, midterm survival was $86 \%$ at 5 years and $85 \%$ at 8 years, with a linearized rate of all-cause death of $3.4 \%$ per patient-year. $^{2}$

The surgical strategy reported in NORCAAD ${ }^{1}$ is by all accounts conservative. Proximally, $73.7 \%$ of patients had

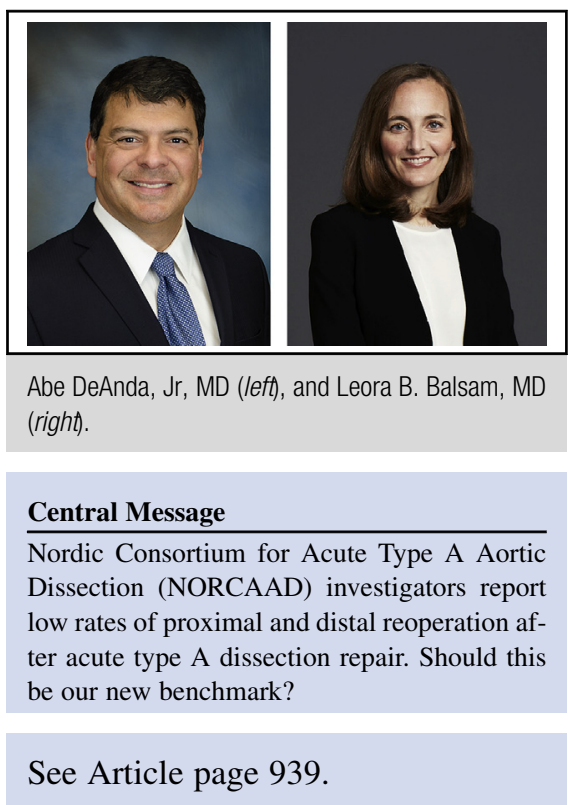

a "root-conservative" approach with a supracoronary graft, whereas $25.2 \%$ had root replacement. Most distal anastomoses were performed open, with $70.6 \%$ to the ascending aorta, $22 \%$ hemiarch replacements, and 5.9\% total arch replacements. Other groups have described a similar conservative approach, including Moon and associates ${ }^{4}$ in their classic article, as well as more contemporary reports from the Stanford group ${ }^{5}$ and the International Registry of Acute Aortic Dissections investigators. ${ }^{3}$ The potential downside of the conservative approach is that more diseased aorta is left behind, which may increase the chance of redissection, dilatation of the residual dissected aorta, and aortic valve incompetence.

Distal or proximal reoperation in the NORCAAD series was low. ${ }^{1}$ Freedom from proximal reoperation was $97.8 \%$ at 5 years, and freedom from distal reoperation was $96.9 \%$ at 5 years. At first glance, these results are encouraging; however is easy to argue that "reoperation is performed" is not a good surrogate for "reoperation is indicated." The latter is difficult to capture in surgical series, particularly those with retrospective data collection.

NORCAAD does give us perspective on the frequency of reoperations in a real-world setting, given that the ATAAD volume of the participating centers was not high. The experience is clearly different than that reported by high-volume referral centers. For example, the Cleveland group reported a probability of distal reintervention of $38 \%$ at 10 years after repair of ATAAD, with $31 \%$ of cases including endovascular techniques. ${ }^{6}$ This aggressive approach to 
reintervention clearly reflects center-specific expertise in aortic surgery (open, endovascular, and hybrid), which will inevitably result in treatment bias.

Of the reoperations related to the distal aorta in NORCAAD, a significant proportion demonstrated progression of disease, or disease not amenable to treatment during the original operation. The frozen elephant trunk technique ${ }^{7}$ promotes distal false lumen thrombosis, and in-so-doing, may lower the incidence of distal aneurysmal dilatation. This technique was not part of the initial treatment strategy in NORCAAD, and it is possible that some of the subsequent thoracoabdominal procedures might have been avoided had it been used. That said, short of using the frozen elephant trunk technique or adopting the arch-first approach of Kouchoukos and colleagues ${ }^{8}$ (which has been well described for chronic type A dissections but not for acute dissections), a certain proportion of patients with type A dissections will eventually need a distal reoperation.

Have NORCAAD investigators set a new benchmark for reoperation rates after ATAAD? The answer is, at best, maybe.

\section{References}

1. Pan E, Gudbjartsson T, Ahlsson A, Fuglsang S, Geirsson A, Hansson EC, et al. Low rate of reoperations after acute type A aortic dissection repair from the Nordic Consortium Registry. J Thorac Cardiovasc Surg. 2018;156:939-48.

2. Olsson C, Ahlsson A, Fuglsang S, Geirsson A, Gunn J, Hansson EC, et al. Medium-term survival after surgery for acute type A aortic dissection is improving. Eur J Cardiothorac Surg. 2017;52:852-7.

3. Di Eusanio M, Trimarchi S, Peterson MD, Myrmel T, Hughes GC, Korach A, et al. Root replacement surgery versus more conservative management during type A acute aortic dissection repair. Ann Thorac Surg. 2014;98: 2078-84.

4. Moon MR, Sundt TM III, Pasque MK, Barner HB, Huddleston CB, Damiano RJ Jr, et al. Does the extent of proximal or distal resection influence outcome for type A dissections? Ann Thorac Surg. 2001;71:1244-9; discussion 1249-50.

5. Chiu P, Trojan J, Tsou S, Goldstone AB, Woo YJ, Fischbein MP. Limited root repair in acute type A aortic dissection is safe but results in increased risk of reoperation. J Thorac Cardiovasc Surg. 2018;155:1-7.e1.

6. Roselli EE, Loor G, He J, Rafael AE, Rajeswaran J, Houghtaling PL, et al. Distal aortic interventions after repair of ascending dissection: the argument for a more aggressive approach. J Thorac Cardiovasc Surg. 2015;149(2 Suppl):117-24.e3.

7. Di Bartolomeo R, Pantaleo A, Berretta P, Murana G, Castrovinci S, Cefarelli M, et al. Frozen elephant trunk surgery in acute aortic dissection. J Thorac Cardiovasc Surg. 2015;149(2 Suppl):S105-9.

8. Kouchoukos NT, Masetti P, Rokkas CK, Murphy SF. Single-stage reoperative repair of chronic type $\mathrm{A}$ aortic dissection by means of the arch-first technique. J Thorac Cardiovasc Surg. 2001;122:578-82. 